\title{
Hippocampal area CAl and remote memory in rats
}

\author{
Amber C. Ocampo, ${ }^{1}$ Larry R. Squire, ${ }^{2,3}$ and Robert E. Clark ${ }^{2,4}$ \\ ${ }^{7}$ Department of Psychology, University of California, San Diego, La Jolla, California 92093, USA; ${ }^{2}$ Veterans Affairs San Diego Healthcare \\ System, San Diego, California 92161, USA; ${ }^{3}$ Departments of Psychiatry, Neurosciences, and Psychology, University of California, San \\ Diego, La Jolla, California 92093, USA; ${ }^{4}$ Department of Psychiatry, University of California, San Diego, La Jolla, California 92093, USA
}

\begin{abstract}
Hippocampal lesions often produce temporally graded retrograde amnesia (TGRA), whereby recent memory is impaired more than remote memory. This finding has provided support for the process of systems consolidation. However, temporally graded memory impairment has not been observed with the watermaze task, and the findings have been inconsistent with context fear conditioning. One possibility is that large hippocampal lesions indirectly disrupt (by retrograde degeneration) the function of areas that project to the hippocampus that are important for task performance or thought to be important for storing consolidated memories. We developed a discrete lesion targeting area CAl, the sole output of the hippocampus to neocortex, and tested the effects of this lesion on recent and remote memory in the watermaze task, in context fear conditioning, and in trace fear conditioning. In all three tasks, recent and remote memory were similarly impaired after CAl lesions. We discuss factors that help to illuminate these findings and consider their relevance to systems consolidation.
\end{abstract}

Systems consolidation refers to the process by which new memories become independent of the hippocampus as they are gradually reorganized into a stable, long-lasting form in neocortex. Support for this idea comes from the phenomenon of temporally graded retrograde amnesia (TGRA), whereby recently acquired memories are more vulnerable to hippocampal damage than older, remotely acquired memories (Frankland and Bontempi 2005; Squire and Bayley 2007; Squire et al. 2015). TGRA after hippocampal damage has been well documented in humans (Kapur and Brooks 1999; Manns et al. 2003) and experimental animals (Zola-Morgan and Squire 1990; Kim and Fanselow 1992; Kim et al. 1995; Clark et al. 2002; Takehara et al. 2003).

An exception to these findings is found in studies with the watermaze task, which tests memory for locations in space. Rats with hippocampal lesions have consistently exhibited severe, ungraded retrograde memory impairment in this task, with remote memory as severely impaired as recent memory (Bolhuis et al. 1994; Mumby et al. 1999; Sutherland et al. 2001; Clark et al. 2005a). The same ungraded impairment was also observed using variations of the watermaze task: cued platform locations (Martin et al. 2005; Clark et al. 2007), annular tracks (Hollup et al. 2001; Clark et al. 2005a), the dry-land Oasis maze (Clark et al. 2005a), and when prolonged training was given early in life (Clark et al. 2005b).

Why is remote memory impaired in rodents with hippocampal lesions when testing occurs in the watermaze? Typically, rodent studies have involved large, excitotoxic hippocampal lesions that encompass areas CA1, CA3, and the dentate gyrus (DG). These large lesions might indirectly disrupt the function of neighboring regions, similar to the disruption observed in area CA1 after excitotoxic lesions of the entorhinal cortex (Miettinen et al. 1998). Indeed, large excitotoxic hippocampal lesions have been reported to cause volume loss in the cortex (Jarrard and Meldrum 1993; Anagnostaras et al. 2001, 2002). The affected regions could include areas important for task performance or cortical areas thought to be important for

\section{Corresponding author: Isquire@ucsd.edu}

Article is online at http://www.learnmem.org/cgi/doi/10.1101//m.045781.117. storing consolidated memories (Frankland et al. 2004; Maviel et al. 2004). These possibilities might be explored by preparing a discrete lesion that targets only area CA1. Because area CA1 provides the sole output pathway from the hippocampus to neocortex (van Strien et al. 2009), a selective CA1 lesion should disrupt hippocampal output to neocortex but preserve the majority of the hippocampus and reduce potential indirect disruption in neighboring regions by sparing the majority of the projections to the hippocampus.

We tested the effects of a CA1 lesion in rats on recent (1-3 d old) and remote (31-33 d old) memory in the watermaze. We also tested the effects of this lesion on context and trace fear conditioning. TGRA has been reported previously for trace fear conditioning after dorsal hippocampal lesions (Quinn et al. 2008). TGRA has also been reported for context fear conditioning after hippocampal lesions (Kim and Fanselow 1992; Maren et al. 1997; Anagnostaras et al. 1999; Winocur et al. 2009), but the literature is mixed and ungraded retrograde memory impairment has also been reported (Lehmann et al. 2007; Sutherland et al. 2008; Sparks et al. 2011; Broadbent and Clark 2013).

\section{Results}

\section{Neurohistological findings}

All lesion animals sustained significant damage to area CA1, including both its dorsal and ventral portions. Figure 1A shows a series of sections from a sham animal and Figure $1 \mathrm{~B}$ shows the extent of a representative CA1 lesion. The average percent damage was $80.2 \%$. Sparing occurred most frequently in the posterior-most and ventral-most extent of CA1. Still, overall damage to vCA1 was substantial. There was also typically some extra-CA1 damage in the DG and area CA3. On average, area CA3 sustained $38.0 \%$

(C) 2017 Ocampo et al. This article is distributed exclusively by Cold Spring Harbor Laboratory Press for the first 12 months after the full-issue publication date (see http://learnmem.cshlp.org/site/misc/terms.xhtml). After 12 months, it is available under a Creative Commons License (Attribution-NonCommercial 4.0 International), as described at http://creativecommons.org/licenses/by-nc/ $4.0 \%$. 

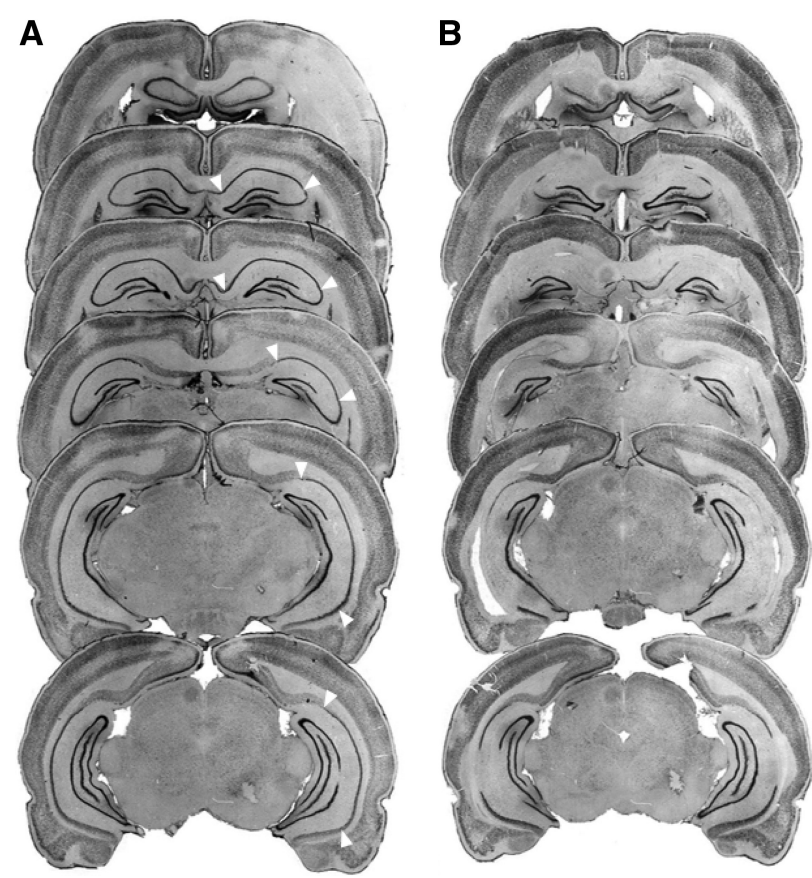

Figure 1. Lesions targeted both dorsal and ventral regions of CA1. Photomicrographs of six coronal histological sections through the hippocampus of a representative $(A)$ sham brain and $(B)$ a brain with a CA1 lesion. The sections are arranged from anterior (top) to posterior (bottom). Arrows indicate the CA1 borders in each section for the sham animal.

damage and the DG sustained $11.5 \%$ damage. Figure 2 reports the percent damage to the separate hippocampal subregions in the lesion groups from the recent and remote conditions. Additionally, it is worth noting that there was no damage to structures immediately adjacent to area CA1 (other than the normal and unavoidable cortical damage observed above the dorsal hippocampus).

Interestingly, there was a significant discrepancy in the amount of damage sustained by the lesion groups in the two conditions. Specifically, lesion rats in the remote condition had less CA1 damage than those in the recent condition (mean \pm SEM: recent: $88.7 \pm 2.1 \%$; remote: $71.7 \pm 3.0 \% ; t_{(30)}=4.7, P<0.0001$ ). This finding may have resulted from differences in rat size at the time of surgery. In any case, despite this potential advantage for the remote group, TGRA was not observed.

\section{Behavioral findings}

\section{Watermaze}

A two-way ANOVA was conducted to test the effects of Group (CA1 versus sham) and Retention Interval (recent versus remote) on the percent time that rats spent in the target quadrant and also in the platform location during the probe test. There was a main effect for Group with both measures (quadrant: $F_{(1,60)}=52.6, P<0.0001$; platform: $\left.F_{(1,60)}=33.4, P<0.0001\right)$, indicating that the two CA1 groups spent less time than the two sham groups in the target quadrant (recent CA1: $22.6 \pm 2.0 \%$, recent sham: $47.2 \pm 3.5 \%$, remote CA1: $27.7 \pm 3.9 \%$, remote sham: $53.7 \pm 4.1 \%$; Fig. $3 \mathrm{~A}$ ) and in the platform location during the probe test (recent CA1: $3.9 \pm$ $0.7 \%$, recent sham: $14.5 \pm 1.8 \%$, remote CA1: $6.9 \pm 2.1 \%$, remote sham: $16.4 \pm 2.0 \%$; Fig. 3B). There was no main effect for Retention Interval with either the quadrant $\left(F_{(1,60)}=2.7, P>0.1\right)$ or the platform measures $\left(F_{(1,60)}=1.9, P>0.1\right)$. Also, there was no Group $\times$ Retention Interval interaction for either measure (quadrant: $F_{(1,60)}=0.04, P>0.1$; platform: $F_{(1,60)}=0.1, P>0.1$ ). Additionally, in both the recent and remote conditions, the CA1 group performed no better than chance (all $t \mathrm{~s}<1.4$; all $P \mathrm{~s}>0.1$ ), while the sham group performed above chance in both conditions and for both measures (all $t \mathrm{~s}>5.8$; all $P \mathrm{~s}<0.05$ ).

\section{Context and trace fear conditioning}

A two-way ANOVA was conducted to test the effects of Group and Retention Interval on the percent time that rats spent freezing during the context fear test and trace fear test. There was a main effect for Group with context fear $\left(F_{(1,60)}=89.8, P<0.0001\right.$; Fig. 4 A), showing that the two CA1 groups froze significantly less than the two sham groups during the context fear test (recent CA1: $4.8 \pm 1.2 \%$, recent sham: $50.5 \pm 5.4 \%$; remote CA1: $12.5 \pm 5.6 \%$, remote sham: $65.2 \pm 6.8 \%)$. The same effect was found with trace fear conditioning $\left(F_{(1,60)}=57.1, P<0.0001\right.$; Fig. $\left.4 \mathrm{~B}\right)$. During the trace fear test, the two CA1 groups were impaired in comparison to controls (recent CA1: $6.5 \pm 1.0 \%$, recent sham: $45.5 \pm 8.3 \%$; remote CA1: $9.2 \pm 2.0 \%$, remote sham: $57.7 \pm 7.8 \%$ ). For the context fear test, there was an additional main effect for Retention Interval $\left(F_{(1,60)}=4.6, P<0.05\right)$, indicating that remote performance was better than recent performance for the combined CA1 and sham groups. However, there was no interaction between Group and Retention Interval $\left(F_{(1,60)}=0.5, P>0.1\right)$. For the trace fear test, there was no main effect for Retention Interval $\left(F_{(1,60)}=1.7, P>0.1\right)$ and no Group $\times$ Retention Interval interaction $\left(F_{(1,60)}=0.7,0.1\right)$.

\section{Behavioral findings excluding rats with extra-CAl damage}

To examine whether the observed behavioral impairments were caused by unintended extra-CA1 damage, we analyzed the data after excluding rats that sustained more than $30 \%$ damage to the combined areas of the DG and CA3. This approach excluded six
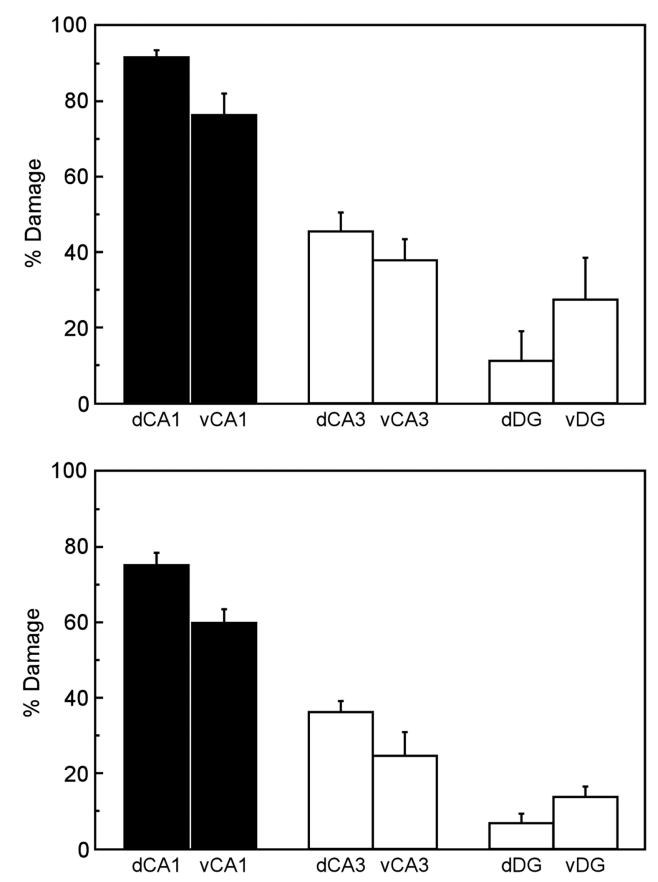

Figure 2. Lesions encompassed the majority of area $C A 1$, while leaving the rest of the hippocampus largely intact. The black bars show the mean percent damage to the CA1 subregion of the hippocampus for animals in the recent condition (top, $n=16$ ) and remote condition (bottom, $n=16$ ). Extra-CA1 damage is shown in white. 

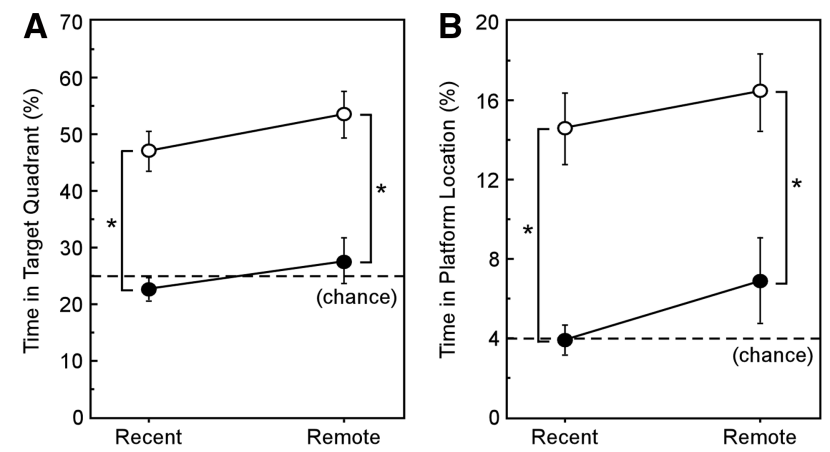

Figure 3. Spatial memory retention in the watermaze was impaired following CA1 lesions in both the recent and remote conditions. $(A)$ Test probe performance measured as the mean percent time spent in the target quadrant. The dashed line indicates chance performance (25\%). $(B)$ Test probe performance measured as the mean percent time spent in the platform location. The dashed line indicates chance performance (4\%). Performance after CA1 lesions is shown in black (recent $n=16$, remote $n=16$ ). Sham performance is shown in white (recent $n=16$, remote $n=16$ ). Error bars indicate SEM; sham scores are well above chance, $P<0.0001 ;\left(^{*}\right) P<0.005$.

rats from the recent CA1 group and two rats from the remote CA1 group. Overall, the results were the same. Two-way ANOVAs demonstrated main Group effects across the three behavioral tests, indicating that the CA1 groups were impaired in comparison to controls during the watermaze probe, context fear, and trace fear tests (all $F \mathrm{~s}>24.4$, all $P \mathrm{~s}<0.0001$ ). Also, there were no main effects for Retention Interval (all $F \mathrm{~s}<3.6$, all $P \mathrm{~s}>0.06$ ) and no Group $\times$ Retention Interval interactions (all $F \mathrm{~s}<0.5$, all $P \mathrm{~s}>0.1$ ). Last, we analyzed the data again after excluding rats with a stricter cutoff for extra-CA1 damage (more than $20 \%$, which excluded nine rats from the recent condition and five rats from the remote condition), and obtained the same results.

\section{Discussion}

Rats were trained in the watermaze, in context fear conditioning, and in trace fear conditioning before receiving either bilateral CA1 lesions or sham surgeries. Surgery was scheduled either 1-3 $\mathrm{d}$ or 31-33 d after training. The CA1 lesion was intended to reduce disruption in neighboring areas that project to the hippocampus with the idea that the restricted CA1 lesion might spare remote memory. Yet, rats that received CA1 lesions long after training were impaired in all three tasks and performed similarly to rats that received CA1 lesions shortly after training. Thus, our findings appear to exclude the possibility that impaired remote memory can be attributed to retrograde disruption in structures projecting to the hippocampus (for example, to DG and CA3).

The findings from all three behavioral tasks provide no support for the standard model of systems consolidation-the idea that the hippocampus plays a gradually diminishing role in the storage of long-term memory. Instead these data are consistent with a number of studies in the rodent literature finding that hippocampus-dependent memories remain hippocampusdependent (Sutherland et al. 2010). One proposal is that during acquisition the hippocampus interferes with, or overshadows, the contribution of other brain areas that would otherwise encode information (Sutherland et al. 2010). A more extended account suggests that, because "the hippocampus receives a broad range of input through convergent cortical afferents, and influences activity dynamics in cortical and subcortical regions... the hippocampal representation [remains] essential for memory retrieval" (Lee et al. 2016). For discussion of other perspectives on the role of the hippo- campus, particularly in remote spatial memory, see Martin et al. (2005).

Nonetheless, there are examples where TGRA has been observed in rodents following hippocampal damage, even in spatial tasks (for reviews, see Frankland and Bontempi 2005; Clark 2011). Although the reasons for this discrepancy (TGRA versus no TGRA) are unclear, we consider here possible factors that could mitigate against finding TGRA in tasks such as ours. We first discuss the results from the watermaze. As in earlier studies with larger lesions (Clark et al. 2005a,b, 2007; Martin et al. 2005), our findings suggest that even limited hippocampal damage impairs performance on this spatial task, regardless of how long after training the damage occurs. Note, though, that spared remote spatial memory has been observed in memory-impaired patients (for review, see Squire and Bayley 2007). For example, patient EP, who developed profound amnesia at age 72 following bilateral medial temporal lobe damage, could mentally navigate the streets in the region where he had grown up (Teng and Squire 1999). Similarly, patient $\mathrm{KC}$, who sustained bilateral damage to the hippocampus and parahippocampal gyrus, as well as regions of neocortex, was able to draw maps of his childhood neighborhood that included an accurate layout of the streets (Rosenbaum et al. 2000). Neither patient could learn or remember new routes (Teng and Squire 1999; Rosenbaum et al. 2000).

Why is remote memory in the watermaze dependent on the hippocampus in rodents when patients with hippocampal damage can remember and navigate environments learned long ago? One possibility is that there are important differences between rodents and humans that affect performance in this task. Support for this idea comes from recent studies of path integration, where subjects search for a target in the dark and then try to return to the start location. Patients with hippocampal lesions performed well at path integration, but rats with hippocampal lesions could not perform the task no matter how simple the outward path (Kim et al. 2013; Sapiurka et al. 2016). It was suggested that path integration in humans can be supported by working memory (in the neocortex), but that rodents cannot construct an effective working memory of spatial environments. Accordingly, for rodents, spatial working memory may require coordination between the hippocampus and neocortex (Sapiurka et al. 2016).

One perspective along these lines suggests that the rodent hippocampus organizes egocentric spatial information from the posterior parietal cortex in order to construct allocentric representations (Byrne et al. 2007). These representations might then
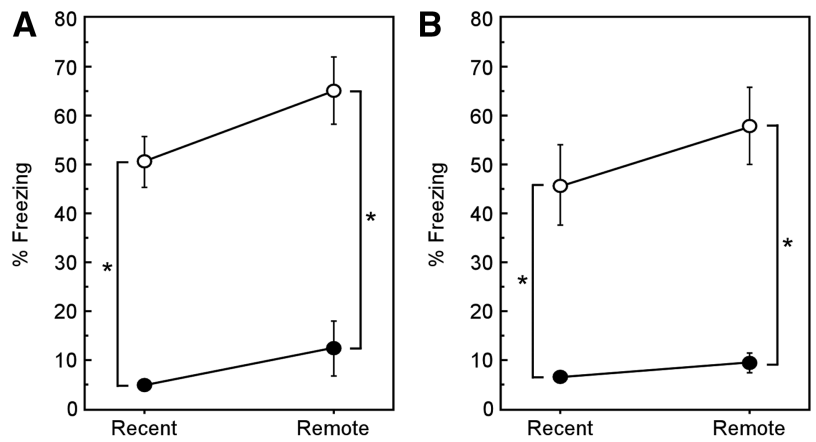

Figure 4. Context and trace fear memory were impaired following CA1 lesions in both the recent and remote conditions. $(A)$ Context fear retention measured as mean percent freezing during the 8-min context test. (B) Trace fear retention during the tone test measured as mean percent freezing during the $240 \mathrm{sec}$ after the onset of the tone. Performance after CA1 lesions is shown in black (recent $n=16$, remote $n=16$ ). Sham performance is shown in white (recent $n=16$, remote $n=16$ ). Error bars indicate SEM; $\left(^{*}\right) P<0.0001$. 
support performance in spatial tasks. If so, hippocampal lesions should affect performance whenever there is a need to engage spatial working memory. In the watermaze, successful performance requires rodents to construct in working memory a coherent representation of the spatial environment and to navigate in the environment. By this account, a hippocampal lesion would impair performance regardless of whether the lesion was made shortly after training or long after training.

We next discuss the results from context fear conditioning. We did not find TGRA, despite the fact that TGRA has frequently been reported after hippocampal lesions with this task (Kim and Fanselow 1992; Maren et al. 1997; Anagnostaras et al. 1999; Winocur et al. 2009). It is notable that, with one exception (Winocur et al. 2009), the lesions in the earlier studies were limited to dorsal hippocampus, whereas our lesion targeted both the dorsal and ventral regions of area CA1. vCA1 originates projections to the amygdala (van Groen and Wyss 1990), which is critical for both recent and remote context fear memory (Maren et al. 1996). One possibility is that the CA1 lesion disrupted activity in the amygdala because of the loss of input from vCA1 (also see Anagnostaras et al. 2001). Note, however, that ungraded retrograde amnesia has sometimes been reported with this task even after limited dorsal hippocampal lesions (Lehmann et al. 2007; Sutherland et al. 2008; Broadbent and Clark 2013). Additionally, context fear acquisition is sometimes spared after large hippocampal lesions (Cho et al. 1999), which would not be expected if large lesions caused significant disruption in the amygdala.

Last, we discuss the results from trace fear conditioning, where again both recent and remote memory were impaired. One earlier study found temporally graded memory impairment in rats after dorsal hippocampal lesions (Quinn et al. 2008). A second study found the same trend, but without clear evidence of spared remote memory (Beeman et al. 2013). There are two important differences between our study and the earlier one that found TGRA (Quinn et al. 2008). First, in the earlier study TGRA was evident across a training-lesion interval of $200 \mathrm{~d}$. We tested remote memory after a training-lesion interval of only 31-33 d. Second, in the earlier study the lesion targeted only dorsal hippocampus, whereas our CA1 lesion targeted both dorsal and ventral hippocampus. As discussed above, it is possible that the ventral portion of our CA1 lesion might have disrupted amygdala function. It is also relevant that the medial prefrontal cortex (mPFC) receives the majority of its hippocampal input from vCA1 (Cenquizca and Swanson 2007), and mPFC lesions impair remote memory for trace fear conditioning (Quinn et al. 2008; Beeman et al. 2013). Accordingly, indirect anterograde disruption of mPFC might be particularly important for understanding the remote memory impairment that we observed in trace fear conditioning.

It is perhaps worth emphasizing that the key issue is not how hippocampal lesions affect recent and remote memory. The key issue is the status of systems consolidation, the idea that the hippocampus becomes less important for memory as time passes after learning, and an idea that hippocampal lesions could potentially illuminate. The principles of systems consolidation are well supported (Kitamura et al. 2017), especially by studies of hippocampal function that use tools and methods more temporally and spatially discrete than ibotenic lesions of hippocampus (Bontempi et al. 1999; Maviel et al. 2004; Wiltgen et al. 2010; Goshen et al. 2011; Hales et al. 2016). Nevertheless, interpretations of retrograde memory impairment have been suggested that do not incorporate a long process of systems consolidation (Sutherland et al. 2010). Still, it is worth considering the possibility that the failure to find TGRA in the current study might reflect specific limitations of the conventional lesion technique and features specific to certain tasks. For example, the spatial demands of the watermaze task may place a burden on working memory, a problem related to the organization of rodent neocortex, not hippocampal function itself. And after large hippocampal lesions, or even CA1 lesions that include ventral hippocampus, disruptive effects may occur in other structures important for fear conditioning.

In summary, rats were impaired in the watermaze, in context fear conditioning, and in trace fear conditioning both when CA1 lesions were made shortly after training and when these lesions were made long after training. Our CA1 lesions were intended to reduce the volume of hippocampal damage and minimize indirect disruption of areas that project to the hippocampus. Our findings could reflect in part the fact that our discrete lesion nevertheless included ventral tissue and that damage to this tissue may have disrupted function in other areas important for fear conditioning. In addition, limitations in spatial working memory in the rodent might be important in understanding watermaze performance. Moving forward, modern methods and tools that improve upon traditional lesion techniques will be useful for expanding the understanding of hippocampal function and memory consolidation.

\section{Materials and Methods}

\section{Subjects}

Subjects were 64 experimentally naive, male Long-Evans rats that were first trained in the watermaze and fear conditioning tasks. Following training, rats were assigned to receive either CA1 or sham lesions (based on watermaze performance at the end of training). Rats in the recent condition received surgery 1-3 d posttraining (CA1 $n=16$, sham $n=16$ ), while rats in the remote condition received surgery $31-33 \mathrm{~d}$ post-training (CA1 $n=16$, sham $n=$ 16). Following recovery from surgery, all rats were tested in both behavioral tasks. In the recent condition, rats weighed between 320 and $350 \mathrm{~g}$ at the beginning of training, and in the remote condition they weighed 290-320 g. Rats were maintained on a 12:12 h light:dark cycle and were initially housed in pairs, then housed individually post-surgery. Food and water were freely available. All experimental procedures were approved by the Institutional Animal Care and Use Committee at the University of California, San Diego.

\section{Apparatus}

\section{Watermaze}

Testing was conducted in a pool of water (1.8-m diameter at the water level) that was rendered opaque by the addition of powdered milk. The testing room contained a number of constant, salient visual cues (posters, objects, equipment). A video camera mounted on the ceiling directly above the pool was used in conjunction with a video tracking system (San Diego Instruments) to record the swim path of each rat. An Atlantis platform (12.7 cm diameter) was used that could be raised or lowered remotely (Spooner et al. 1994). In the lowered position, the platform was undetectable and unavailable. In the raised position $(1.5 \mathrm{~cm}$ below the surface of the water), the platform remained invisible, but provided a means to escape the water.

\section{Context and trace fear conditioning}

Conditioning and testing were conducted in eight identical fearconditioning chambers housed within polyvinyl chloride (PVC) sound-attenuating cubicles (Med Associates Inc). The conditioning chambers were constructed from aluminum and Plexiglas. The floor of each chamber consisted of 19 stainless steel rods $(0.5 \mathrm{~cm}$ diameter) spaced $1.6 \mathrm{~cm}$ apart (center to center). The rods were connected to a shock generator and scrambler. Each chamber was fitted with a ventilation fan that also provided background noise $(75 \mathrm{~dB})$. A video camera connected to a computer was positioned at the front of each chamber, which digitally recorded behavior for off-line analysis using Video Freeze V2.1.0 software (Med Associates Inc.). 


\section{Behavioral training}

\section{Watermaze acquisition}

Rats were given eight trials per day for $10 \mathrm{~d}$. The first and fifth trials of each day were reinforced probe trials. During these trials, rats were placed in the water facing the pool wall at one of four start points (counterbalanced across animals). The platform remained lowered for the first $60 \mathrm{sec}$ of the probe trial. The platform was then raised, and the rat had an additional $60 \mathrm{sec}$ to reach the platform. If the rat did not reach the platform within the additional $60 \mathrm{sec}$, it was guided to the platform by the experimenter. After escaping the water, the rat remained on the platform for $30 \mathrm{sec}$ and was then returned to its home cage. During the remaining six standard training trials, the platform remained in the raised position, allowing the rats to escape from the water. Rats were given up to 2 min to escape the water before being guided to the platform by the experimenter. As with the probe trials, the rats remained on the platform for $30 \mathrm{sec}$ before being returned to their home cage. Following training, rats were assigned to receive either CA1 or sham lesions based on their performance during the first probe trial on the last day of training. Specifically, the assignment was based on the percentage of time that the rat spent in the quadrant of the pool that had contained the platform $($ chance $=25 \%)$.

\section{Context and trace fear conditioning}

Following completion of watermaze training, rats underwent context and trace fear conditioning. Each rat was placed in a fearconditioning chamber for $\sim 25 \mathrm{~min}$. The session began with a 240 -sec baseline period, followed by five tone-shock trials. Each trial consisted of a 20 -sec pure tone $(5 \mathrm{kHz}, 90 \mathrm{~dB})$, a 30 -sec stimulusfree trace interval, and a 2 -sec footshock $(1.0 \mathrm{~mA})$. The inter-trial interval was $240 \mathrm{sec}$ and the conditioning session ended $60 \mathrm{sec}$ after the last trial.

\section{Surgery}

At the prescribed time after training, rats received either excitotoxic CA1 lesions or sham surgeries. Anesthesia was maintained throughout surgery with isoflurane gas $(0.8 \%-2.0 \%$ isoflurane delivered in $\mathrm{O}_{2}$ at $1 \mathrm{~L} / \mathrm{min}$ ). The rat was placed in a Kopf stereotaxic instrument, and the incisor bar was adjusted until Bregma was level with Lambda. For CA1 lesions, ibotenic acid (IBO; Biosearch Technologies) dissolved in $0.1 \mathrm{M}$ PBS (concentration: $10 \mathrm{mg} / \mathrm{mL}$, $\mathrm{pH}$ 7.4) was injected along the dorsoventral CA1 axis (bilaterally) using a $10 \mathrm{~mL}, 30-\mathrm{g}$ Hamilton syringe, which was held in a Kopf microinjector (model 5000) and mounted on a stereotaxic frame. The syringe was first lowered to the target coordinate and left in place for $1 \mathrm{~min}$. After injection (at a rate of $0.1 \mathrm{~mL} / \mathrm{min}$ ), the syringe stayed at the target coordinate for $2 \mathrm{~min}$ to prevent IBO from spreading up the syringe tract upon its retraction. For certain injection sites in ventral CA1 (noted below), the syringe was left in place for $5 \mathrm{~min}$ to ensure that IBO would not spread up the syringe track (where it might cause unintended damage to CA3 or the DG). IBO $(0.025 \mu \mathrm{L})$ was injected at each site (unless otherwise noted). Injections were made at multiple locations. All coordinates are in millimeters, anteroposterior (AP) relative to Bregma, mediolateral (ML) relative to Lambda, and dorsoventral (DV) relative to the brain surface at $-4.8 \mathrm{~mm}$ from Bregma and $\pm 4.2 \mathrm{~mm}$ from Lambda: $\mathrm{AP}-2, \mathrm{ML} \pm 1, \mathrm{DV}-2.9 ; \mathrm{AP}-3.6, \mathrm{ML} \pm 1, \mathrm{DV}-2.7$; $\mathrm{AP}$ -3.6, ML \pm 2 , DV -1.9 ; AP -4.5, ML \pm 1.4 , DV -3.3; AP -4.5, ML $\pm 2.7, \mathrm{DV}-1.8$; $\mathrm{AP}-4.5, \mathrm{ML} \pm 4.5, \mathrm{DV}-7.9$ (waited 5 min before retracting syringe); $\mathrm{AP}-5.3, \mathrm{ML} \pm 3, \mathrm{DV}-1.7 ; \mathrm{AP}-5.3, \mathrm{ML} \pm 4.8, \mathrm{DV}$ -8 (waited $5 \mathrm{~min}$ before retracting syringe); $\mathrm{AP}-5.3, \mathrm{ML} \pm 4.8, \mathrm{DV}$ -2.4; $\mathrm{AP}-5.3, \mathrm{ML} \pm 5.8, \mathrm{DV}-7.5 ; \mathrm{AP}-5.3, \mathrm{ML} \pm 5.8, \mathrm{DV}-5.7 ; \mathrm{AP}$ $-5.3, \mathrm{ML} \pm 5.8, \mathrm{DV}-3.9$; $\mathrm{AP}-6.3, \mathrm{ML} \pm 5.4, \mathrm{DV}-3$ (injected $0.05 \mu \mathrm{L}$ IBO); AP -6.3, ML $\pm 6.3, \mathrm{DV}-5.7$ (injected $0.05 \mu \mathrm{L} \mathrm{IBO}$ ). Rats given sham surgeries underwent the same surgical procedures up to the point of the craniotomy. Once awake and responsive, each rat was returned to its home cage for a 12-14 d recovery period.

\section{Behavioral retention tests}

\section{Watermaze retention test}

Following recovery from surgery, rats were given a reinforced probe trial (as described in Behavioral Training) to test their memory for the trained platform location. As in training, the start location for the trial was counterbalanced across animals. Spatial memory retention was calculated by measuring the percentage of time each rat spent in the quadrant of the pool where the platform had been located during training (chance $=25 \%$ ), as well as the percentage of time that each rat spent in the circular zone directly above the platform location $($ chance $=4 \%)$.

\section{Context fear retention test}

Following the watermaze test probe, rats were tested for their retention of context fear memory. Rats were placed in the fearconditioning chambers that they were originally conditioned in for $8 \mathrm{~min}$, while freezing behavior was measured. Context fear retention was calculated as the percentage of time that each rat spent freezing during the 8-min test.

\section{Trace fear test}

The next day, rats were habituated to a new context for $8 \mathrm{~min}$. This new context involved a different fear-conditioning chamber with triangular walls, flat plastic flooring, altered lighting, new olfactory cues, a modified transportation experience, and a new experimenter (who handled each animal for two 5-min sessions prior to this phase of testing). One day later, rats were returned to the context in which they were habituated the previous day and given an 8-min tone test to assess their retention of trace fear memory. The test began with a 240 -sec baseline period, followed by a 20 -sec tone, and then $220 \mathrm{sec}$ without tone. Trace fear retention was calculated as the percentage of time that each rat spent freezing during the $240 \mathrm{sec}$ after the onset of the tone.

\section{Histology}

At completion of testing, the rats were administered an overdose of sodium pentobarbital and perfused transcardially with buffered $0.9 \% \mathrm{NaCl}$ solution followed by $10 \%$ formaldehyde solution (in $0.1 \mathrm{M}$ phosphate buffer). The brains were removed and cryoprotected in $20 \%$ glycerol $/ 10 \%$ formaldehyde. Coronal sections (50 $\mu \mathrm{m})$ were cut with a freezing microtome beginning at the level of the anterior commissure and continuing caudally through the length of the hippocampus. Every fifth section was mounted and stained with thionin to assess the extent of the lesions.

An additional series of sections (with the same section intervals) was prepared for immunolocalization of neuron-specific nuclear protein $(\mathrm{NeuN})$ by using an anti-NeuN $(1: 15,000$, Chemicon) monoclonal mouse antibody. A biotinylated antimouse IgG $(\mathrm{H}+\mathrm{L})(1: 1,000$, Vector BA-2000) was used as the secondary antibody. Images of the NeuN-stained tissue sections were acquired using a DM6000 microscope (Leica Microsystems, Inc.). The images from every other mounted section were then analyzed using Stereo Investigator software (mbf Bioscience; MicroBrightField). The volumes of spared tissue were calculated using the Cavalieri method, which involved overlaying a sampling grid (one grid point $/ 150 \mu^{2}$ ) on the tissue image and counting the total number of grid points in contact with each of the following anatomical regions: dorsal(d)CA1, ventral(v)CA1, dCA3, vCA3, $\mathrm{dDG}$, and vDG. The total estimated volume of the spared tissue in each region was calculated by summing the section thickness, the section sampling fraction, and the number of selected grid points per section multiplied by the area associated with each grid point. We then determined the percent damage in each region, calculated by dividing the volume of damaged tissue by the average volume of tissue in the sham rats and multiplying by 100 . This analysis was conducted for all lesion rats and eight sham rats in the recent and the remote conditions. Calculations were conducted separately for rats in the two conditions. The experimenter was not blind to the retention intervals during the analysis. 


\section{Acknowledgments}

We thank J. Hales, L. Johnson, M. Sapiurka, S. Saturday, and P. Cintora for assistance. This work was supported by the Medical Research Service of the Department of Veterans Affairs (101CX000359 to L.R.S.; I01BX001076 to R.E.C.), NSF grant (\#SMA-1041755) to the Temporal Dynamics of Learning Center at UCSD, and NIMH (MH24600). The manuscript has been seen and approved by all of the authors.

\section{References}

Anagnostaras SG, Maren S, Fanselow MS. 1999. Temporally graded retrograde amnesia of contextual fear after hippocampal damage in rats: within-subjects examination. J Neurosci 19: 1106-1114.

Anagnostaras SG, Gale GD, Fanselow MS. 2001. The hippocampus and contextual fear conditioning: recent controversies and advances. Hippocampus 11: 8-17.

Anagnostaras SG, Gale GD, Fanselow MS. 2002. The hippocampus and Pavlovian fear conditioning: reply to Bast et al. Hippocampus 12: 561-565.

Beeman CL, Bauer PS, Pierson JL, Quinn JJ. 2013. Hippocampus and medial prefrontal cortex contributions to trace and contextual fear memory expression over time. Learn Mem 20: 336-343.

Bolhuis JJ, Stewart CA, Forrest EM. 1994. Retrograde amnesia and memory reactivation in rats with ibotenate lesions to the hippocampus or subiculum. Q J Exp Psychol B 47: 129-150.

Bontempi B, Laurent-Demir C, Destrade C, Jaffard R. 1999. Time-dependent reorganization of brain circuitry underlying long-term memory storage. Nature 400: 671-675.

Broadbent NJ, Clark RE. 2013. Remote context fear conditioning remains hippocampus-dependent irrespective of training protocol, training-surgery interval, lesion size, and lesion method. Neurobiol Learn Mem 106: 300-308.

Byrne P, Becker S, Burgess N. 2007. Remembering the past and imagining the future: a neural model of spatial memory and imagery. Psychol Rev 114: $340-375$.

Cenquizca LA, Swanson LW. 2007. Spatial organization of direct hippocampal field CA1 axonal projections to the rest of the cerebral cortex. Brain Res Rev 56: 1-26.

Cho YH, Friedman E, Silva AJ. 1999. Ibotenate lesions of the hippocampus impair spatial learning but not contextual fear conditioning in mice. Behav Brain Res 98: 77-87.

Clark RE. 2011. Eyeblink conditioning and systems consolidation: an ironic yet powerful pairing. Learn Mem 95: 118-124.

Clark RE, Broadbent NJ, Zola SM, Squire LR. 2002. Anterograde amnesia and temporally graded retrograde amnesia for a nonspatial memory task after lesions of hippocampus and subiculum. J Neurosci 22: 4663-4669.

Clark RE, Broadbent NJ, Squire LR. 2005a. Hippocampus and remote spatia memory in rats. Hippocampus 15: 260-272.

Clark RE, Broadbent NJ, Squire LR. 2005b. Impaired remote spatial memory after hippocampal lesions despite extensive training beginning early in life. Hippocampus 15: 340-346.

Clark RE, Broadbent NJ, Squire LR. 2007. The hippocampus and spatial memory: findings with a novel modification of the water maze. $J$ Neurosci 27: 6647-6654.

Frankland PW, Bontempi B. 2005. The organization of recent and remote memories. Nat Rev Neurosci 6: 119-130.

Frankland PW, Bontempi B, Talton LE, Kaczmarek L, Silva AJ. 2004. The involvement of the anterior cingulate cortex in remote contextual fear memory. Science 304: 881-883.

Goshen I, Brodsky M, Prakash R, Wallace J, Gradinaru V, Ramakrishnan C, Deisseroth K. 2011. Dynamics of retrieval strategies for remote memories. Cell 147: 678-689.

Hales JB, Ocampo AC, Broadbent NJ, Clark RE. 2016. Consolidation of spatial memory in the rat: findings using zeta-inhibitory peptide. Neurobiol Learn Mem 136: 220-227.

Hollup SA, Kjelstrup KG, Hoff J, Moser M-B, Moser E. 2001. Impaired recognition of the goal location during spatial navigation in rats with hippocampal lesions. J Neurosci 21: 4505-4513.

Jarrard LE, Meldrum BS. 1993. Selective excitotoxic pathology in the rat hippocampus. Neuropathol Appl Neurobiol 19: 381-389.

Kapur N, Brooks DJ. 1999. Temporally-specific retrograde amnesia in two cases of discrete bilateral hippocampal pathology. Hippocampus 9: 247-254.

Kim JJ, Fanselow MS. 1992. Modality-specific retrograde amnesia of fear. Science 256: 675-677.

Kim JJ, Clark RE, Thompson RF. 1995. Hippocampectomy impairs the memory of recently, but not remotely, acquired trace eyeblink conditioned responses. Behav Neurosci 109: 195-203.
Kim S, Sapiurka M, Clark RE, Squire LR. 2013. Contrasting effects on path integration after hippocampal damage in humans and rats. Proc Natl Acad Sci 110: 4732-4737.

Kitamura T, Ogawa SK, Roy DS, Okuyama T, Morrissey MD, Smith LM, Redondo RL, Tonegawa S. 2017. Engrams and circuits crucial for systems consolidation of a memory. Science 356: 73-78.

Lee JQ, Zelinski EL, McDonald RJ, Sutherland RJ. 2016. Heterarchic reinstatement of long-term memory: a concept on hippocampal amnesia in rodent memory research. Neurosci Biobehav Rev 71: 154-166.

Lehmann H, Lacanilao S, Sutherland RJ. 2007. Complete or partial hippocampal damage produces equivalent retrograde amnesia for remote contextual fear memories. Eur J Neurosci 25: 1278-1286.

Manns JR, Hopkins RO, Squire LR. 2003. Semantic memory and the human hippocampus. Neuron 38: 127-133.

Maren S, Aharonov G, Fanselow MS. 1996. Retrograde abolition of conditional fear after excitotoxic lesions in the basolateral amygdala of rats: absence of a temporal gradient. Behav Neurosci 110: 718-726.

Maren S, Aharonov G, Fanselow MS. 1997. Neurotoxic lesions of the dorsal hippocampus and Pavlovian fear conditioning in rats. Behav Brain Res 88: $261-274$.

Martin SJ, de Hoz L, Morris RG. 2005. Retrograde amnesia: neither partial nor complete hippocampal lesions in rats result in preferential sparing of remote spatial memory, even after reminding. Neuropsychologia 43: 609-624.

Maviel T, Durkin TP, Menzaghi F, Bontempi B. 2004. Sites of neocortical reorganization critical for remote spatial memory. Science 305: 96-99.

Miettinen R, Kotti T, Tuunanen J, Toppinen A, Riekkinen P Sr, Halonen T. 1998. Hippocampal damage after injection of kainic acid into the rat entorhinal cortex. Brain Res 813: 9-17.

Mumby DG, Astur RS, Weisend MP, Sutherland RJ. 1999. Retrograde amnesia and selective damage to the hippocampal formation: memory for places and object discriminations. Behav Brain Res 106: 97-107.

Quinn JJ, Ma QD, Tinsley MR, Koch C, Fanselow MS. 2008. Inverse temporal contributions of the dorsal hippocampus and medial prefrontal cortex to the expression of long-term fear memories. Learn Mem 15: 368-372.

Rosenbaum RS, Priselac S, Köhler S, Black SE, Gao F, Nadel L, Moscovitch M. 2000. Remote spatial memory in an amnesic person with extensive bilateral hippocampal lesions. Nat Neurosci 3: 1044-1048.

Sapiurka M, Squire LR, Clark RE. 2016. Distinct roles of hippocampus and medial prefrontal cortex in spatial and nonspatial memory. Hippocampus 26: $1515-1524$.

Sparks FT, Lehmann H, Hernandez K, Sutherland RJ. 2011. Suppression of neurotoxic lesion-induced seizure activity: evidence for a permanent role for the hippocampus in contextual memory. PLoS One 6: e27426.

Spooner RI, Thomson A, Hall J, Morris RG, Salter SH. 1994. The Atlantis platform: a new design and further developments of Buresova's on-demand platform for the water maze. Learn Mem 1: 203-211.

Squire LR, Bayley PJ. 2007. The neuroscience of remote memory. Curr Opin Neurobiol 17: 185-196.

Squire LR, Genzel L, Wixted JT, Morris RG. 2015. Memory consolidation. Cold Spring Harb Perspect Biol 7: a021766.

Sutherland RJ, Weisend MP, Mumby D, Astur RS, Hanlon FM, Koerner A, Thomas MJ, Wu Y, Moses SN, Cole C, et al. 2001. Retrograde amnesia after hippocampal damage: recent vs. remote memories in two tasks. Hippocampus 11: 27-42.

Sutherland RJ, O'Brien J, Lehmann H. 2008. Absence of systems consolidation of fear memories after dorsal, ventral, or complete hippocampal damage. Hippocampus 18: 710-718.

Sutherland RJ, Sparks FT, Lehmann H. 2010. Hippocampus and retrograde amnesia in the rat model: a modest proposal for the situation of systems consolidation. Neuropsychologia 48: 2357-2369.

Takehara K, Kawahara S, Kirino Y. 2003. Time-dependent reorganization of the brain components underlying memory retention in trace eyeblink conditioning. J Neurosci 23: 9897-9905.

Teng E, Squire LR. 1999. Memory for places learned long ago is intact after hippocampal damage. Nature 400: 675-677.

van Groen T, Wyss JM. 1990. Extrinsic projections from area CA1 of the rat hippocampus: olfactory, cortical, subcortical, and bilateral hippocampal formation projections. J Comp Neurol 302: 515-528.

van Strien NM, Cappaert NL, Witter MP. 2009. The anatomy of memory: an interactive overview of the parahippocampal-hippocampal network. Nat Rev Neurosci 10: 272-282.

Wiltgen BJ, Zhou M, Cai Y, Balaji J, Karlsson MG, Parivash SN, Li W, Silva AJ. 2010. The hippocampus plays a selective role in the retrieval of detailed contextual memories. Curr Biol 20: 1336-1344.

Winocur G, Moscovitch M, Fogel S, Rosenbaum RS, Sekeres M. 2005. Preserved spatial memory after hippocampal lesions: effects of extensive experience in a complex environment. Nature 8: 273-275.

Zola-Morgan SM, Squire LR. 1990. The primate hippocampal formation: evidence for a time-limited role in memory storage. Science 250: 288-290.

Received April 19, 2017; accepted in revised form July 17, 2017. 


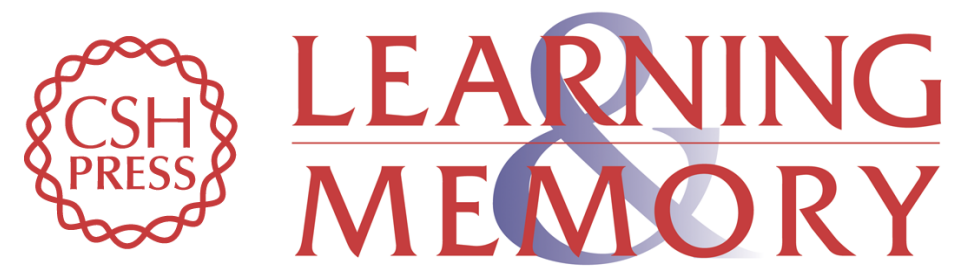

\section{Hippocampal area CA1 and remote memory in rats}

Amber C. Ocampo, Larry R. Squire and Robert E. Clark

Learn. Mem. 2017, 24:

Access the most recent version at doi:10.1101/Im.045781.117

References This article cites 52 articles, 15 of which can be accessed free at: http://learnmem.cshlp.org/content/24/11/563.full.html\#ref-list-1

Creative This article is distributed exclusively by Cold Spring Harbor Laboratory Press for the Commons first 12 months after the full-issue publication date (see

License http://learnmem.cshlp.org/site/misc/terms.xhtml). After 12 months, it is available under a Creative Commons License (Attribution-NonCommercial 4.0 International), as described at http://creativecommons.org/licenses/by-nc/4.0/.

Email Alerting Receive free email alerts when new articles cite this article - sign up in the box at the Service top right corner of the article or click here. 